\title{
Increase of Pyramidal Tract Fractional Anisotropy on MRI after Stem Cell Transplantation in ALS Patients
}

\author{
Martínez $\mathrm{HR}^{1,2^{\star}}$, González-Garza $\mathrm{MT}^{2}$, Moreno-Cuevas $\mathrm{JE}^{2}$, Caro-Osorio $\mathrm{E}^{1}$, Gil-Valadez $\mathrm{A}^{1}$, Ocañas $\mathrm{CEE}^{2}$, Marioni SS ${ }^{2}$, Hernandez-Torre $\mathbf{M}^{3}$ \\ ${ }^{1}$ Neurology and Neurosurgery Institute, TEC Salud, Monterrey, Nuevo Leon, Mexico \\ 2Stem Cell Therapy Service, National School of Medicine, Monterrey, Nuevo Leon, Mexico, 64710, Mexico \\ ${ }^{3}$ Research and Innovation, TEC Salud. Instituto Tecnológico de Monterrey, Mexico
}

*Corresponding author: Hector R. Martinez, Neurology and Neurosurgery Institute. Mexico, Tel: +52 (81) 8888 0676; Fax: +52 (81) 8888 0675; Email: drhectormtz@yahoo.com

Received date: Aug 22, 2014, Accepted date: Oct 27, 2014, Published date: Nov 03, 2014

Copyright: (c) 2014 Martínez HR, et al. This is an open-access article distributed under the terms of the Creative Commons Attribution License, which permits unrestricted use, distribution, and reproduction in any medium, provided the original author and source are credited.

\begin{abstract}
Background and Purpose: Amyotrophic lateral sclerosis (ALS) is characterized by the selective death of motor neurons. Cortical neuron loss is associated with axonal degeneration along specific white matter tracts. Fractional anisotropy (FA) determined by Magnetic Resonance (MR) might detect integrity or changes in brain white matter pathways. This study was aimed to analyze pyramidal tract changes in ALS patients submitted to stem cell transplantation into the frontal motor cortices.

Patients and Methods: Fourteen patients with definite ALS were included. After signing their informed consent, the patients underwent magnetic resonance imaging (MRI). The pyramidal tract (PT) from the corona radiata to medulla oblongata was evaluated by quantitative voxel-wise analysis, including FA and diffusion tensor tractography derived from MR diffusion tensor imaging (MR-DTI) at baseline and 6 months after CD 133+ stem cells transplantation into the frontal motor cortices. FA changes were analyzed with the Tract-Based Spatial Statistics software (FMRIB Software Library, Oxford University). Statistical analyzes among FA before and after stem cells transplantation were performed using the SPSS, v.17.
\end{abstract}

Results: Improvement in FA was observed in the PT of the whole group when compared at baseline with 6 months after stem cell transplantation $(p=0.05)$. FA significative changes were observed in the PT at the corona radiata $(p=0.05)$ and internal capsule regions $(p=0.03)$. FA changes were observed in the PT at the mesencephalic and bulbar regions. However, they were not statistically significant.

Conclusions: FA positive changes suggest recovery of the PT in ALS subjects after stem cells transplantation. These changes could possible be explained not only by cell replacement but also by modifications of the extracellular motor neuronal environment, through trophic and neuroprotective effects of stem cells.

Keywords: MRI; Tractography; Fractional anisotropy; Amyotrophic Lateral Sclerosis; ALS; ALSFRSr; Autologous stem cell; Stem cell transplantation

\section{Introduction}

Amyotrophic lateral sclerosis (ALS) is a late-onset neurodegenerative disorder characterized by rapid deterioration and the selective death of motor neurons (MN) in the cerebral cortex, brain stem, and spinal cord [1-3]. A wide variety of clinical manifestations are present early in the course of ALS [4]. The clinical features are attributable to the superimposition of motor deficits occurring in the upper motor neurons (UMNs) and lower motor neurons (LMNs). The motor phenotypes are highly heterogeneous and are defined by: 1) the body region of onset; 2 ) the relative mix of UMN and LMN involvement; and 3) the rate of progression [5]. Clinical evidence of both UMN and LMN damage and its progressive spread are required for the diagnosis of ALS [4,6,7]. The mean survival of ALS patients from diagnosis ranges from 15.7 months to 47 months, according to different series $[6,8]$.
PT axons mostly arise from UMN of the primary motor cortex $(60 \%)$, the remainder comes from supplementary motor areas and from the parietal lobe [9]. The PT fibers end directly in LMN (alpha and gamma neurons) of the spinal cord. Loss of UMN produces axonal degeneration in the PT. At the present time, integrity of PT and white matter tracts may be evaluated in a voxel-based morphometry (VBM), which assess the regional distribution of white matter loss [10]. Fractional anisotropy (FA) derived from MR diffusion tensor imaging (MR-DTI) is an informative measure of axonal fiber degeneration and myelin breakdown [11]. Several studies have investigated changes in FA between patients with neurological disorders and healthy controls, with the aim of improving diagnosis and monitoring disease progression [12]. Previous reports have described a decreased FA values at various sites along the PT in ALS patients $[13,14]$. Decrements in the FA are interpreted as reflecting axonal degeneration $[13,15]$. MR imaging technology is changing dramatically our understanding of ALS and has been used to aid in the clinical process of establishing a diagnosis of sporadic ALS and to monitor disease progression [16-20]. 
Citation: Martínez HR, González-Garza MT, Moreno-Cuevas JE, Caro-Osorio E, Gil-Valadez A, et al. (2014) Increase of Pyramidal Tract Fractional Anisotropy on MRI after Stem Cell Transplantation in ALS Patients. J Neurol Neurophysiol 5: 244. doi: $10.4172 / 2155-9562.1000244$

Page 2 of 7

There is no effective therapy for ALS patients. Riluzole is the only medication approved by the U.S. Food and Drug Administration for the treatment of this disorder. However, this drug only slightly delays disease progression [4]. Stem cell therapy is considered an alternative method for treating neurodegenerative disorders, including ALS $[21,22]$. Stem cell transplantation is a potential therapeutic strategy, based not only on cell replacement but also on the modification of the extracellular motor neuronal environment, through trophic and neuroprotective effects [23]. A variety of cell sources have been considered for cell therapy [24,22].

Adult stem cells are specialized cells found within many tissues of the body. These cells can be easily isolated from the peripheral blood or bone marrow (BM) [25-30]. It has been demonstrated that stem cells isolated from peripheral blood of ALS patients, can be induced to differentiate into preneurons or stem cells isolated from human BM are capable to differentiate into neurons [31]. These differentiated cells express nestin, neuron-specific enolase, neuron-specific nuclear protein, glial fibrillary acidic protein, neurofilaments, TAU, NURR1, and neuron-specific tubulin 1 [27-29, 31-33]. Some studies have reported that these cells have synaptic transmission capacities [32,33].

Clinical studies using stem cells in humans have been described in Huntington's disease, Parkinson's disease, spinal cord injury, stroke patients, and Batten's disease [23,34-38]. No animal model reproduces all the salient features of ALS particularly the involvement of the pyramidal tract. Furthermore, mesenchymal stem cell differentiate into neurons in in vitro and in vivo studies [27-29]. Therefore some researchers have attempted stem-cell-based approaches for the treatment of ALS patients. Current clinical trials are based principally on two main transplantation strategies: the systemic $[39,40]$ and the local approaches [22, 41-46]. Mesenchymal stem cell transplantation into the spinal cords of ALS patients has been described, and the authors reported this method as safe [41]. Recently it has also been described that CD133+ stem cells transplantation into the frontal motor cortices in ALS patients is a safe and well-tolerated procedure $[43,44,47]$.

In the present study we compared MR-DTI and FA changes of the PT in ALS patients at baseline and 6 months after mesenchymal stem cell transplantation into the frontal motor cortices. The aim of this uncontrolled, open-label non-randomized clinical trial was to assess a possible improvement of UMN status through FA changes in the PT.

\section{Methods and Patients}

\section{Study subjects}

All patients were recruited and evaluated for their eligibility at the Neuroscience Center of the Hospital San José Tec de Monterrey and the Neurology Service of the Hospital Universitario UANL, Monterrey NL, México. The protocol was approved by the Institutional Review Board of the Hospital San Jose Tec de Monterrey and Tecnologico de Monterrey School of Medicine (registration number 01122005), and all participants signed an informed consent form. A trained neurologist conducted examinations to confirm the diagnosis of definite ALS, according to the well-established El Escorial clinical and neurophysiological criteria $[48,49]$. Patients with a current or past history of neurological disease other than ALS and those enrolled in other clinical trials were excluded. The inclusion criteria were: (a) confirmed ALS according to the El Escorial clinical and neurophysiological criteria; (b) no structural damage to the brain or spinal cord on cervical and cranial magnetic resonance imaging (MRI); (c) pulmonary function test showing a forced vital capacity (FVC) of at least of $30 \%$; and (d) appropriate nutritional status, with a body mass index of at least $19 \mathrm{~kg} / \mathrm{m} 2$. The exclusion criteria were: (a) severe bulbar affection (FVC less than 30\%); (b) inadequate nutritional status or a body mass index lower than $19 \mathrm{~kg} / \mathrm{m} 2$; (c) tracheostomy; (d) presence of systemic disorders, such as malignant neoplasm, cardiovascular disease (decompensated hypertension, ischaemic cardiopathy and arrhythmia), previous stroke, or coagulation abnormalities; and (e) evidence of cervical spondylotic myelopathy or structural abnormalities on MRI, as previously described [43,44].

The neurological examination consisted of testing for muscle tone, stretch reflexes, pathological reflexes, and the Medical Research Council scale for grading muscle power and strength [50]. The ALS Functional Rating Scale Revised (ALSFRS-R) [51], which is the most widely used and extensively validated global scale for assessing motor function in ALS, was administered to all ALS patients. This scale is weighted toward limb and bulbar function, and gives a total severity score out of 48 possible points. Patients with greater disability have a lower score. A mini mental state examination (MMSE) and a cognitive neuropsychological test were performed for all ALS patients before surgery. The entire clinical evaluation lasted 30-45 $\mathrm{min}$ and was performed at baseline, 1 day and 1, 3 and 6 months after surgery.

\section{Stem cell preparation}

After their informed consent was obtained, the patients in the treatment group received a subcutaneous daily dose of $300 \mu \mathrm{g}$ of filgrastim (Neupogen, Basel, Switzerland) for three days [43,44]. This drug, a human granulocyte colony-stimulating factor (G-CSF) produced with recombinant DNA technology, acts on hematopoietic cells by binding to specific cell surface receptors and thus stimulating cellular proliferation, differentiation, and some end cell functional activation. Absolute nucleated hematopoietic cell counts have been reported to increase in diseased as well as in normal subjects receiving G-CSF [52,53].

On the day following the final dose of G-CSF, the patients were admitted to the hospital, and a white blood cell count (WBC) was obtained. Also, a Mahurkar catheter was placed into the right subclavian vein. Through this catheter, peripheral blood mononuclear cells were isolated by leukapheresis (Baxter CS 3000+, Deerfield, IL, USA; or Haemonetics MCS, Braintree, MA, USA). This procedure lasted for $2 \mathrm{~h}$. A $2 \mathrm{~mL}$ sample of cerebrospinal fluid (CSF) was also obtained by lumbar puncture after the apheresis procedure. The cells obtained were washed three times with phosphate-buffered saline. The CD133+ immunoreactive cells in the cell suspension were conjugated with anti-human CD133+ superparamagnetic microbeads and isolated in a magnetic field over a MiniMACS separation column (Miltenyi Biotech, Gladbach, Germany). The enrichment of the CD133+ cells in the patient samples was confirmed by fluorescence-activated cell sorting. The cells were counted with a Beckman Z2 Coulter Counter (Fullerton, CA, USA) and 3.0-5.0 x106 cells were suspended in $0.3 \mathrm{~mL}$ of autologous CSF and dispensed into sterile tubes $[43,44]$. The total preparation of the CD133+ stem cells took $4 \mathrm{~h}$, and the patients were then sent to the operating room.

\section{Surgery}

To avoid respiratory complications, the procedure was performed while the patients were awake, under mild sedation and local 
Citation: Martínez HR, González-Garza MT, Moreno-Cuevas JE, Caro-Osorio E, Gil-Valadez A, et al. (2014) Increase of Pyramidal Tract Fractional Anisotropy on MRI after Stem Cell Transplantation in ALS Patients. J Neurol Neurophysiol 5: 244. doi: $10.4172 / 2155-9562.1000244$

Page 3 of 7

anesthesia. The stem cells were transplanted bilaterally into the frontal motor cortex with neuronavigation guidance (Vector Vision 2, Brain Lab AG, Munich, Germany). Based on MRI scan for neuronavigation, the motor cortex strip was identified, and the target was defined 3-4 $\mathrm{cm}$ from the midline. The positions at which the bur holes were to be made were identified with the navigation system. After an incision of the dura, the suspension of CD133+ stem cells in CSF was injected into the cortex to a depth of $7 \mathrm{~mm}$ using a Hamilton syringe held by a mechanical arm, to maintain its stability during the procedure. Ninety seconds was the injection time. After this period, the syringe was held on site for an additional 60 seconds. Finally, haemostatic gel was applied (Gelfoam, Pfizer, Belgium). The vascular structures and subarachnoid spaces were avoided. The patients were hospital discharged on the following day.

\section{Image acquisition}

MRI for neuronavigation was performed at baseline. MRI-DTI tractography and FA of the PT were obtained at baseline and 6 months after stem cells transplantation. In a lying position, without respiratory support, ALS subjects were submitted to this study by using a $1.5-\mathrm{T}$ magnetic resonance equipment (Philips Medical Systems, Eindhoven, Holland) with a whole-body gradient coil, and an extended MRI workspace with neuroimaging software. Conventional studies were made of axial, sagittal, and coronal views. The axial pulse sequences included three-dimensional fast field echo high-resolution T1- and T2-weighted images, fluid-attenuated inversion recovery (FLAIR) long TR images, and proton-density-weighted images. T2-weighted TSE images in sagittal and coronal sequences were also obtained, together with sagittal sequences on FLAIR. DTI sequence was acquired 3 times to improve SNR. These sequences had the purpose of measuring FA of the PT and the integrity of the whole brain white matter in a quantitative voxel-wise analysis [54]. DTI images were exported and analyzed with TBSS (Tract-Based Spatial Statistics) (Software Library, Oxford University) [54,55] the information was then transferred to DICOM format.

A Neuroradiologist and a PhD-Physicist blinded to the research protocol analyzed and measured the FA of the PT in regions of interest (ROI) that were named as: bulbar (ROI-1), mescencephalic (ROI-2), posterior limb of internal capsule (ROI-3) and the Corona Radiata (ROI-4). Differences in FA among the defined brain regions between baseline MRI and at 6 months after stem cells transplantation were investigated using TBSS. FA measured in the whole PT in all ALS patients at baseline were compared with FA obtained at six months after stem cells transplantation, comparisons among FA right and left side of each ROI of the PT were also performed before and after stem cells transplantation. Voxel-wise statistical analysis of the FA data was carried out using TBSS part of FSL $[56,57]$

\section{Data analysis}

The variables are described as means \pm standard deviations and medians (25th and 75th quartiles), for normal and non-normal data, respectively. Univariate comparisons of the demographic (age and sex) and clinical variables (baseline ALSFRS-R, FVC score, and site of onset) were analyzed with the $\chi 2$ test. Voxel-wise statistical analysis of the FA data was carried out using TBSS part of FSL [56]. A student ttest was performed for comparisons among FA before and after stem cells transplantation in the whole PT as well as right and left of each ROI of the PT, significance among differences was tested at the 5\% level. All statistical analyses were performed with the SPSS 17.0 software package (SPSS, Chicago, IL, USA).

\section{Results}

Fourteen subjects with definite ALS underwent autologous stem cell transplantation into the frontal motor cortex. They were 8 males and 6 females with ages ranging from 26 to 61 years (mean age $46.2 \pm 10.3$ years). Bulbar-onset ALS was diagnosed in $21.4 \%(\mathrm{n}=3)$ of patients, spinal-onset ALS in 78.5\% $(\mathrm{n}=11)$, and no patient had bulbospinal involvement at onset. The motor phenotypes were heterogeneous at the time of the baseline physical examination. In $50 \%(n=7)$ of patients, the LMN-UMN were equally affected, whereas $35.7 \%(\mathrm{n}=5)$ of patients presented with predominant UMN involvement and only $14 \%$ of patients $(n=2)$ had a predominantly LMN phenotype. Among the 14 ALS patients included, the interval between clinical onset and diagnosis (median onset to diagnosis interval) was 9.5 months (25th, 75th quartiles: 7,15 ) (Table 1). The pulmonary function test at baseline showed a median FVC of 55.5\% (25th, 75th quartiles: 39.5, 74 ). The median baseline ALSFRS-R score was 29 points (25th, 75th quartiles: $24,34.8$ ). There were no abnormalities on the laboratory tests, which included coagulation profiles and electrocardiograms. No changes in cognitive function, as demonstrated with MMSE at one month after the procedure in the whole group. No long-term neurologic complications inherited to the procedure (up to 6 months) were observed. MRI studies did not indicate tumour or other brain structural changes at 6 months after stem cells transplantation. Clinical parameters evaluated at 6 months after transplantation showed a median ALSFRS-R score of 28 points (25th, 75th quartiles: $21,37.5)$.

\begin{tabular}{|c|c|c|c|c|c|c|c|}
\hline Subject & $\begin{array}{l}\text { Age: } \\
\text { (years) }\end{array}$ & $\begin{array}{l}\text { Sex: } \\
\text { (Male:M or Female: } \\
\text { F) }\end{array}$ & Site of Onset & 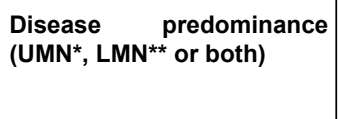 & ODI + (months) & DBI ๆ (months) & $\begin{array}{l}\text { Outcome (at } 6 \\
\text { months) }\end{array}$ \\
\hline ALS Subject 1 & 30 & $\mathrm{~F}$ & Bulbar & UMN/LMN & 7 & 18 & Alive \\
\hline ALS Subject 2 & 26 & M & Spinal & UMN/LMN & 14 & 24 & Alive \\
\hline ALS Subject 3 & 55 & $\mathrm{~F}$ & Spinal & LMN & 17 & 60 & Alive \\
\hline ALS Subject 4 & 51 & $M$ & Spinal & UMN & 6 & 27 & Alive \\
\hline ALS Subject 5 & 48 & M & Spinal & UMN/LMN & 20 & 11 & Alive \\
\hline ALS Subject 6 & 48 & M & Spinal & UMN/LMN & 11 & 11 & Alive \\
\hline
\end{tabular}


Citation: Martínez HR, González-Garza MT, Moreno-Cuevas JE, Caro-Osorio E, Gil-Valadez A, et al. (2014) Increase of Pyramidal Tract Fractional Anisotropy on MRI after Stem Cell Transplantation in ALS Patients. J Neurol Neurophysiol 5: 244. doi: $10.4172 / 2155-9562.1000244$

Page 4 of 7

\begin{tabular}{|c|c|c|c|c|c|c|c|}
\hline ALS Subject 7 & 61 & $\mathrm{~F}$ & Spinal & UMN/LMN & 6 & 23 & Alive \\
\hline ALS Subject 8 & 55 & $\mathrm{~F}$ & Bulbar & UMN & 10 & 5 & Alive \\
\hline ALS Subject 9 & 60 & $\mathrm{~F}$ & Spinal & LMN & 12 & 1 & Alive \\
\hline ALS Subject 10 & 28 & M & Spinal & UMN & 10 & 15 & Alive \\
\hline ALS Subject 11 & 53 & $\mathrm{~F}$ & Bulbar & UMN & 8 & 6 & Alive \\
\hline ALS Subject 12 & 51 & M & Spinal & UMN/LMN & 16 & 8 & Alive \\
\hline ALS Subject 13 & 35 & M & Spinal & UMN/LMN & 7 & 6 & Alive \\
\hline ALS Subject 14 & 43 & M & Spinal & UMN & 31 & 31 & Alive \\
\hline
\end{tabular}

Table 1: Demography in 14 ALS patients showing site of onset, motor neuron predominance, interval between clinical onset to diagnosis (ODI), diagnosis to baseline interval (DBI); ${ }^{*} \mathrm{UMN}$ : Upper Motor Neuron, ${ }^{*} \mathrm{LMN}$ : Lower Motor Neuron, +ODI: Onset to diagnosis interval $9 \mathrm{DBI}$ : diagnosis to baseline interval.

A neuroradiologist reviewed MRI at baseline and described isolated and small high intensity signal in regions of the PT in 3 out 14 ALS subjects mostly localized in the region of internal capsule. The FA derived from MRI-DTI was analyzed and reported by a PhD Physicist blinded to the procedure (Table 2). The mean value of the FA in the entire PT including all ROI in the 14 ALS cases revealed an increment in the FA when comparing baseline results with data obtained at 6 months after stem cells transplantation $(\mathrm{p}=0.05)$. Positive increments in the FA were also observed in the whole PT at corona radiata level (ROI 4) $(\mathrm{p}=0.05)$ and internal capsule region (ROI 3) $(\mathrm{p}=0.03)$. Although increments in the FA were observed in the whole PT in the mescencephalic (ROI 2) and bulbar region (ROI 1) at six months after transplantation, these changes were no statistically significant $(\mathrm{p}=0.18$ and $\mathrm{p}=0.20$ respectively) (Table 2 , Figure 1 ).

\begin{tabular}{|l|l|l|l|}
\hline & FA means & $(\mathrm{n}=14)$ & $\mathrm{P}$ values $(95 \% \mathrm{Cl}){ }^{*}$ \\
\hline $\begin{array}{l}\text { Region of Interest } \\
\text { (ROI) }\end{array}$ & $\begin{array}{l}\text { Pre- } \\
\text { transplant }\end{array}$ & $\begin{array}{l}\text { Post- } \\
\text { Transplant }\end{array}$ & \\
\hline Piramidal tract total & 0.433 & 0.448 & $0.05(-0.035$ to -0.000$)$ \\
\hline Piramidal tract left & 0.433 & 0.448 & $0.05(-0.03$ to -0.000$)$ \\
\hline Piramidal tract right & 0.433 & 0.448 & $0.07(-0.373$ to -0.001$)$ \\
\hline $\begin{array}{l}\text { Bulbar region total } \\
\text { (ROI 1) }\end{array}$ & 0.429 & 0.440 & $0.20(-0.034$ to -0.008$)$ \\
\hline $\begin{array}{l}\text { Bulbar region right } \\
\text { (ROI 1) }\end{array}$ & 0.427 & 0.439 & $0.22(-0.382$ to -0.009$)$ \\
\hline $\begin{array}{l}\text { Bulbar region left } \\
\text { (ROI 1) }\end{array}$ & 0.431 & 0.442 & $0.20(-0.031$ to -0.007$)$ \\
\hline $\begin{array}{l}\text { Mesencephalic } \\
\text { region total (ROI 2) }\end{array}$ & 0.511 & 0.524 & $0.18(-0.038$ to -0.008$)$ \\
\hline $\begin{array}{l}\text { Mesencephalic } \\
\text { region right (ROI 2) }\end{array}$ & 0.507 & 0.519 & $0.31(-0.038$ to -0.013$)$ \\
\hline $\begin{array}{l}\text { Mesencephalic } \\
\text { region left (ROI 2) }\end{array}$ & 0.514 & 0.530 & $0.10(-0.041$ to -0.002$)$ \\
\hline $\begin{array}{l}\text { Internal capsule } \\
\text { region total (ROI 3) }\end{array}$ & 0.513 & 0.532 & $0.03(-0.041$ to -0.002$)$ \\
\hline
\end{tabular}

\begin{tabular}{|l|l|l|l|}
\hline $\begin{array}{l}\text { Internal capsule } \\
\text { region right (ROI 3) }\end{array}$ & 0.509 & 0.525 & $0.04(-0.036$ to -0.000$)$ \\
\hline $\begin{array}{l}\text { Internal capsule } \\
\text { region left (ROI 3) }\end{array}$ & 0.517 & 0.539 & $0.05(-0.051$ to -0.000$)$ \\
\hline $\begin{array}{l}\text { Corona radiata } \\
\text { region total (ROI 4) }\end{array}$ & 0.366 & 0.384 & $0.05(-0.410$ to -0.000$)$ \\
\hline $\begin{array}{l}\text { Corona radiata } \\
\text { region right (ROI 4) }\end{array}$ & 0.370 & 0.390 & $0.07(-0.484$ to -0.002$)$ \\
\hline $\begin{array}{l}\text { Corona radiata } \\
\text { region left (ROI 4) }\end{array}$ & 0.362 & 0.377 & $0.04(-0.348$ to -0.000$)$ \\
\hline
\end{tabular}

Table 2: Fractional Anisotropy (FA) in cerebral regions of interest (ROI). Comparison of the FA values in different ROI in ALS subjects before and after stem cell transplantation into the frontal motor cortices; ${ }^{\star}$ 95\% Confidence Interval

FA changes were compared in left and right PT in each ROI between baseline values (pre-transplant) and those at six months after the procedure (post-transplant). Increments in FA of the entire PT were only significant on the left PT $(p=0.05)$. The right entire PT showed no significant increment, but demonstrated a clear statistical trend towards that goal $(\mathrm{p}=0.07)$. Analysis by specific ROI demonstrated differences among the entire left and right PT in ROI 4 (corona radiata) $(\mathrm{p}=0.04$ and $\mathrm{p}=0.07$ respectively and in ROI3 (internal capsule) of the entire PT on the left and right sides ( $\mathrm{p}=0.05$ and $\mathrm{p}=0.04$ respectively). Increments in FA were also detected in left and right ROI 1 and ROI 2. However, they were not statistically significant (Figure 1).

\section{Discussion}

There is no effective treatment for ALS patients. Life expectancies range from 15 to 47 months after presentation $[8,6]$ even after Riluzole treatment. Stem cell transplantation is a potential therapeutic strategy for ALS patients, as well as for other neurodegenerative disorders $[41,43,44,45,34-38,22]$, and may act by cell replacement or by modifying the extracellular motor neuronal environment. Adult stem cells isolated in vivo from human BM or peripheral blood can differentiate into neural cells. Furthermore, it has been demonstrated 
Citation: Martínez HR, González-Garza MT, Moreno-Cuevas JE, Caro-Osorio E, Gil-Valadez A, et al. (2014) Increase of Pyramidal Tract Fractional Anisotropy on MRI after Stem Cell Transplantation in ALS Patients. J Neurol Neurophysiol 5: 244. doi: $10.4172 / 2155-9562.1000244$

Page 5 of 7

that CD133+ stem cells isolated from the peripheral blood can differentiate into neurons $[27,28,31]$.

Recently, several authors have described preliminary results of stem cell therapy in ALS patients [40,41,42,43,4539,22]. Different local routes for stem cell transplantation have been reported in these patients, including intraspinal [41,46], intrathecal [45], and directly into the frontal motor cortex $[8,43,44]$. Previous studies using a systemic approach $[39,40]$ in ALS patients were based on the impairment of the blood-brain barrier observed in animal models of ALS [58], but this topic remains controversial [59].

We recently described autologous $\mathrm{CD} 133+$ stem cell transplantation into the frontal motor cortices of 10 patients with definite ALS, based on the scientific rationale of improving the UMN function in these patients $[43,44]$. Safety and feasibility of CD133+ stem cell transplantation into the frontal motor cortices of 67 definite ALS patients was also recently described by our group [44]

The pathological hallmark in ALS is the degeneration of both UMN and LMN [4,6,7]. Assessment of UMN damage in ALS patients is suggested only by neurological evaluation. The FA derived of MRIDTI has shown potential in objectively assessing UMN injury [16,-20]. Decrement in the FA of the PT in ALS subjects suggests UMN damage. Since the PT originates from the UMN, FA analysis of this tract may help us to confirm clinical diagnosis of UMN damage in ALS.

In the present study we compared modification of the FA in the PT of patients with ALS before inclusion to a research protocol of autologous mesenchymal stem cell transplantation into the frontal motor cortices (FA baseline) and at 6 months after the procedure (FA post transplant). The aim of this clinical trial was to assess a possible improvement of UMN status through FA changes in the PT.

We have observed an increment in the FA in all ROI of the PT analyzed in the present series. However, statistically significant positive changes were only observed in the upper regions of the PT (ROI-4 and ROI-3) such as corona radiata and internal capsule (Figure 1, Table 2). Increments in the FA were also observed in the PT after stem cells transplantation in mesencephalic and bulbar regions. However, in these ROI, FA changes did not reach statistically significant values (figure 1). The site where stem cells were injected and probably the time the MRI-FA follow-up was performed may explain these positive changes in the FA only in internal capsule and corona radiata after the procedure.

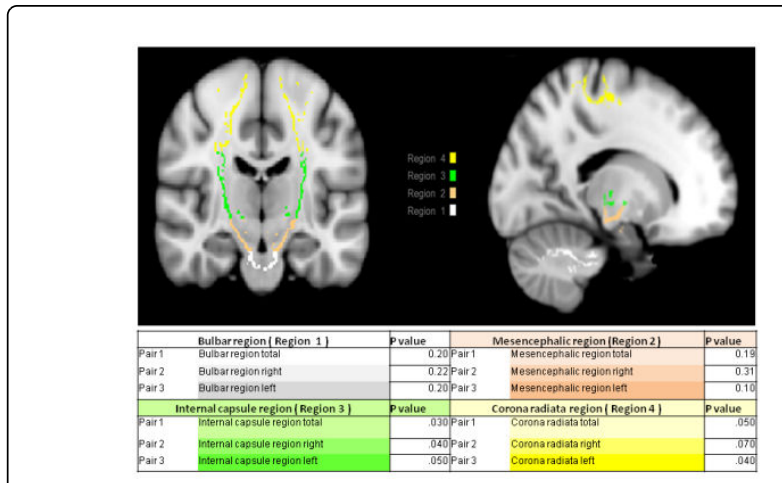

Figure 1: MRI coronal (left) and sagittal view (right). Fractional anisotropy of the PT was analyzed, measured and compared in 4 regions of interest (ROI) named as bulbar (ROI-1, in white), mescencephalic (ROI-2, brown), posterior limb of internal capsule (ROI-3, green)) and Corona Radiata (ROI-4, yellow). Differences between baseline and after stem cells transplantation MRI-FA are shown. Only ROI 3 and 4 that are located close to the site of transplantation showed statistically significant increment in FA in comparison to baseline FA. In the corona radiata, increase in FA was found when left and right sides were measured and compared in total $(p=0.05), F A$ in this ROI showed statistically significant increment only in left side $(\mathrm{p}=04)$.

In the present series, clinical parameters in transplanted patients were followed up by the ALSFRS-R [51], since is the most widely used and extensively validated global scale for assessing motor function in ALS. The median baseline ALSFRS-R score was 29 points and at 6 months after transplantation, the median ALSFRS-R score was 28 points. It have been described an average decline of 1.1 ALSFRS-R score per month (-13.32 per year) [46], in our cases have observed a clinical stabilization during follow up (6 months)

There was no correlation among FA increases in the corona radiata and internal capsule regions and the ALFRS-R score. The absence of correlation is explained by the fact that ALSFRS-R is weighted toward limb and bulbar function and not restricted to evaluate the UMN function. Moreover motor phenotypes in ALS are highly heterogeneous, as it was observed in the present series, where $50 \%$ of cases showed similar affection of UMN and LMN.

Stem cell transplantation into the frontal motor cortices in ALS patients may act by cell replacement or by modifying the extracellular motor neuronal environment. If both of these possibilities occurred in our ALS patients, mescencephalic and bulbar regions are expected to improve in a period longer than 6 months follow up (Figure 1). Increase of pyramidal tract fractional anisotropy on MRI after stem cell transplantation suggests that CD 133+ stem cells either improved axonal functionality or promoted axonal recovery, however, possible neuronal replacement may also explain positive changes in regions 3 and 4 of the PT.

According to the present study, stem-cell transplantation in ALS patients slightly delays disease progression and produced clinical stability as it was shown in ALSFRS-R score. Slow clinical progression and longer survival rate has also been described with this transplantation procedure in ALS patients $[43,44]$. A remarkable issue of stem cell transplantation into the frontal motor cortices is that is performed under local anesthesia and with light short-term sedation 
Citation: Martínez HR, González-Garza MT, Moreno-Cuevas JE, Caro-Osorio E, Gil-Valadez A, et al. (2014) Increase of Pyramidal Tract Fractional Anisotropy on MRI after Stem Cell Transplantation in ALS Patients. J Neurol Neurophysiol 5: 244. doi: $10.4172 / 2155-9562.1000244$

Page 6 of 7

avoiding general anesthesia. Moreover, no serious adverse events were observed in our cases. Pyramidal tract FA measured by MRI may help us to confirm clinical diagnosis of UMN involvement in ALS subjects. This neuroimaging method may also be used to determine effectiveness of different therapies in clinical trials. It will be necessary to further evaluate the efficacy of this procedure in ALS patients under controlled conditions.

\section{Conclusion}

FA derived from MRI-DTI revealed an increment in the PT at six months after stem cell transplantation. Further studies and controlled clinical trials with a greater number of patients are necessary to define the usefulness of stem-cell therapy in patients with definite ALS. Additionally, we consider that FA analysis is warranted to detect early UMN degeneration and to monitor its progress or modifications by therapeutic approaches in patients with ALS.

\section{Acknowledgments}

This project was funded in part by the Instituto Tecnologico y de Estudios Superiores de Monterrey (grant number CAT 014) and the Zambrano Hellion Foundation. We are grateful to Marcela Rojas (psychologist) who performed the neuropsychological tests and Juan Francisco Molina MD who performed demographic analysis.

\section{References}

1. Toft MH, Gredal O, Pakkenberg B (2005) The size distribution of neurons in the motor cortex in amyotrophic lateral sclerosis. J Anat 207: 399-407.

2. Mills KR (2003) The natural history of central motor abnormalities in amyotrophic lateral sclerosis. Brain 126: 2558-2566.

3. Ringel SP, Murphy JR, Alderson MK, Bryan W, England JD, et al. (1993) The natural history of amyotrophic lateral sclerosis. Neurology 43: 1316-1322.

4. Lomen-Hoerth C (2008) Amyotrophic lateral sclerosis from bench to bedside. Semin Neurol 28: 205-211.

5. Ravits JM, La Spada AR (2009) ALS motor phenotype heterogeneity, focality, and spread: deconstructing motor neuron degeneration. Neurology 73: 805-811.

6. Zoccolella S, Beghi E, Palagano G, Fraddosio A, Guerra V, et al. (2008) Analysis of survival and prognostic factors in amyotrophic lateral sclerosis: a population based study. J Neurol Neurosurg Psychiatry 79: 33-37.

7. Rowland LP, Shneider NA (2001) Amyotrophic lateral sclerosis. N Engl J Med 344: 1688-1700.

8. Martinez HR, Molina-Lopez JF, Cantu-Martinez L, Gonzalez-Garza MT Moreno-Cuevas, et al. (2011): Survival and clinical features in hispanic amyotrophic lateral sclerosis patients. Amyotroph. Lateral Sc. 12:199-205.

9. Davidoff RA (1990) The pyramidal tract. Neurology 40: 332-339.

10. Agosta F, Chiò A, Cosottini M, De Stefano N, Falini A, et al. (2010) The present and the future of neuroimaging in amyotrophic lateral sclerosis. AJNR Am J Neuroradiol 31: 1769-1777.

11. Ciccarelli O, Behrens TE, Johansen-Berg H, Talbot K, Orrell RW, et al. (2009) Investigation of white matter pathology in ALS and PLS using tract-based spatial statistics. Hum Brain Mapp 30: 615-624.

12. Horsfield MA, Jones DK (2002) Applications of diffusion-weighted and diffusion tensor MRI to white matter diseases - a review. NMR Biomed 15: 570-577.

13. Sage CA, Peeters RR, Görner A, Robberecht W, Sunaert S (2007) Quantitative diffusion tensor imaging in amyotrophic lateral sclerosis. Neuroimage 34: 486-499.
14. Sach M, Winkler G, Glauche V, Liepert J, Heimbach B, et al. (2004) Diffusion tensor MRI of early upper motor neuron involvement in amyotrophic lateral sclerosis. Brain 127: 340-350.

15. Agosta F, Pagani E, Rocca MA, Caputo D, Perini M, et al. (2007) Voxelbased morphometry study of brain volumetry and diffusivity in amyotrophic lateral sclerosis patients with mild disability. Hum Brain Mapp 28: 1430-1438.

16. Ciccarelli O, Catani M, Johansen-Berg H, Clark C, Thompson A (2008) Diffusion-based tractography in neurological disorders: concepts, applications, and future developments. Lancet Neurol 7: 715-727.

17. Hong YH, Sung JJ, Kim SM, Park KS, Lee KW, et al. (2008) Diffusion tensor tractography-based analysis of the pyramidal tract in patients with amyotrophic lateral sclerosis. J Neuroimaging 18: 282-287.

18. Ciccarelli O, Behrens TE, Altmann DR, Orrell RW, Howard RS, et al. (2006) Probabilistic diffusion tractography: a potential tool to assess the rate of disease progression in amyotrophic lateral sclerosis. Brain 129: 1859-1871.

19. Hong YH, Lee KW, Sung JJ, Chang KH, Song IC (2004) Diffusion tensor MRI as a diagnostic tool of upper motor neuron involvement in amyotrophic lateral sclerosis. J Neurol Sci 227: 73-78.

20. Toosy AT, Werring DJ, Orrell RW, Howard RS, King MD, et al. (2003) Diffusion tensor imaging detects corticospinal tract involvement at multiple levels in amyotrophic lateral sclerosis. J Neurol Neurosurg Psychiatry 74: 1250-1257.

21. Cova L, Ratti A, Volta M, Fogh I, Cardin V, et al. (2004) Stem cell therapy for neurodegenerative diseases: the issue of transdifferentiation. Stem Cells Dev 13: 121-131.

22. Silani V, Cova L, Corbo M, Ciammola A, Polli E (2004) Stem-cell therapy for amyotrophic lateral sclerosis. Lancet 364: 200-202.

23. Kim SU, de Vellis J (2009) Stem cell-based cell therapy in neurological diseases: a review. J Neurosci Res 87: 2183-2200.

24. Jozwiak S, Habich A, Kotulska K, Sarnowska A, Kropiwnicki T, et al. (2010): Intracerebroventricular transplantation of cord blood-derived neural progenitors in a child with severe global brain ischemic injury. Cell Med. 1: 71-80.

25. Delcroix GJ, Schiller PC, Benoit JP, Montero-Menei CN (2010) Adult cell therapy for brain neuronal damages and the role of tissue engineering. Biomaterials 31: 2105-2120.

26. Choumerianou DM, Dimitriou H, Kalmanti M (2008) Stem cells: promises versus limitations. Tissue Eng Part B Rev 14: 53-60.

27. Yamamoto $R$, Ishikawa $M$, Tanaka N, Kamei N, Nakanishi $K$, et al. (2008) CD133+ cells from human peripheral blood promote corticospinal axon regeneration. Neuroreport 19: 799-803.

28. Borlongan CV, Evans A, Yu G, Hess DC (2005) Limitations of intravenous human bone marrow CD133+ cell grafts in stroke rats. Brain Res 1048: 116-122.

29. Long X, Olszewski M, Huang W, Kletzel M (2005) Neural cell differentiation in vitro from adult human bone marrow mesenchymal stem cells. Stem Cells Dev 14: 65-69.

30. Aejaz HM, Aleem AK, Parveen N, Khaja MN, Narusu ML, et al. (2007) Stem cell therapy-present status. Transplant Proc 39: 694-699.

31. Gonzalez-Garza MA, Martinez HR, Caro-Osorio E, Cruz-Vega D, Hernandez-Torre M, et al. (2013). Differentiation of CD 133+ Stem Cells from Amyotrophic Lateral Sclerosis Patients Into Preneuron cells. Stem Cells Translational Medicine 2: 129-135.

32. Cho KJ, Trzaska T, Greco SJ, McArdle J, Wang FS (2005) Neurons derived from human mesenchymal stem cells show synaptic transmission and can be induced to produce the neurotransmitter substance $\mathrm{P}$ by interleukin-1 alpha. Stem Cells 23:383-391.

33. Hung SC, Cheng H, Pan CY, Tsai MJ, Kao LS, et al. (2002) In vitro differentiation of size-sieved stem cells into electrically active neural cells. Stem Cells 20: 522-529.

34. Schwarz SC, Schwarz J (2010) Translation of stem cell therapy for neurological diseases. Transl Res 156: 155-160. 
Citation: Martínez HR, González-Garza MT, Moreno-Cuevas JE, Caro-Osorio E, Gil-Valadez A, et al. (2014) Increase of Pyramidal Tract Fractional Anisotropy on MRI after Stem Cell Transplantation in ALS Patients. J Neurol Neurophysiol 5: 244. doi: $10.4172 / 2155-9562.1000244$

Page 7 of 7

35. Lima C, Pratas-Vital J, Escada P, Hasse-Ferreira A, Capucho C, et al. (2006) Olfactory mucosa autografts in human spinal cord injury: a pilot clinical study. J Spinal Cord Med 29: 191-203.

36. Moviglia GA, Fernandez Vina R, Brizuela JA, Saslavsky J, Vrsalovic F, et al. (2006) Combined protocol of cell therapy for chronic spinal cord injury. Report on the electrical and functional recovery of two patients. Cytotherapy 8:202-209.

37. Isacson $\mathrm{O}(2003)$ The production and use of cells as therapeutic agents in neurodegenerative diseases. Lancet Neurol 2: 417-424.

38. Kondziolka D, Wechsler L, Goldstein S, Meltzer C, Thulborn KR, et al. (2000) Transplantation of cultured human neuronal cells for patients with stroke. Neurology 55: 565-569.

39. Appel SH, Engelhardt JI, Henkel JS, Siklos L, Beers DR, et al. (2008) Hematopoietic stem cell transplantation in patients with sporadic amyotrophic lateral sclerosis. Neurology 71: 1326-1334.

40. Cashman N, Tan LY, Krieger C, Madler B, Mackay A et al. (2008) Pilot study of granulocyte colony stimulating factor (G-CSF)-mobilized peripheral blood stem cells in amyotrophic lateral sclerosis (ALS). Muscle Nerve 37:620-662.

41. Mazzini L, Ferrero I, Luparello V, Rustichelli D, Gunetti M, et al. (2010) Mesenchymal stem cell transplantation in amyotrophic lateral sclerosis: A Phase I clinical trial. Exp Neurol 223: 229-237.

42. Deda H, Inci MC, Kürekçi AE, Sav A, Kayihan K, et al. (2009) Treatment of amyotrophic lateral sclerosis patients by autologous bone marrowderived hematopoietic stem cell transplantation: a 1-year follow-up. Cytotherapy 11: 18-25.

43. Martinez HR, Gonzalez-Garza MT, Moreno-Cuevas JE, Caro E, Gutierrez-Jimenez E, et al. (2009) Stem-cell transplantation into the frontal motor cortex in amyotrophic lateral sclerosis patients. Cytotherapy 11: 26-34.

44. Martínez HR, Molina-Lopez JF, González-Garza MT, Moreno-Cuevas JE, Caro-Osorio E, et al. (2012) Stem cell transplantation in amyotrophic lateral sclerosis patients: methodological approach, safety, and feasibility. Cell Transplant 21: 1899-1907.

45. Janson CG, Ramesh TM, During MJ, Leone P, Heywood J (2001) Human intrathecal transplantation of peripheral blood stem cells in amyotrophic lateral sclerosis. J Hematother Stem Cell Res 10: 913-915.

46. Riley J, Glass J, Feldman EL, Polak M, Bordeau J, et al. (2014) Intraspinal stem cell transplantation in amyotrophic lateral sclerosis: a phase I trial, cervical microinjection, and final surgical safety outcomes. Neurosurgery 74: 77-87.
47. Martanez HR, Salazar-Marioni S, Escamilla-Ocaaas CE, Gonzalez-Garza MT, Moreno-Cuevas JE (2014) Amyotrophic lateral sclerosis in pregnancy: clinical out come during the post-partum period after stem cell transplantation into the frontal motor cortex. Cytotherapy 16: 402-405.

48. Brooks BR, Miller RG, Swash M, Munsat (2000): El Escorial revisited: revised criteria for the diagnosis of amyotrophic lateral sclerosis. Amyotroph. Lateral Scler. Other Motor Neuron Disord. 1: 293-299.

49. Miller RG, Munsat TL, Swash M, Brooks BR (1999) Consensus guidelines for the design and implementation of clinical trials in ALS. World Federation of Neurology committee on Research. J Neurol Sci 169: 2-12.

50. John J (1984) Grading of muscle power: comparison of MRC and analogue scales by physiotherapists. Medical Research Council. Int J Rehabil Res 7: 173-181.

51. Kaufmann P, Levy G, Thompson JL, Delbene ML, Battista V, et al. (2005) The ALSFRSr predicts survival time in an ALS clinic population. Neurology 64: 38-43.

52. Hashimoto S, Itoh M, Nishimura M, Asai T (2002) Effect of filgrastim administration for steady-state mobilization of peripheral blood stem cells. Ther Apher 6: 431-436.

53. Krager N, Renges H, Krager W, Gutensohn K, et al. (2000): A randomized comparison of once versus twice daily recombinant human granulocyte colony stimulating factor (filgrastim) for stem cell mobilization in healthy donors for allogeneic transplantation. Br. J. Haematol. 111: 761-765.

54. Smith SM, Jenkinson M, Johansen-Berg HD, Rueckert TE, Nichols CE, et al. (2006): Tract-based spatial statistics: Voxelwise analysis of multisubject diffusion data. Neuroimage 31: 1487-1505.

55. Smith SM, Jenkinson M, Woolrich MW, Beckmann CF, Behrens TE, et al. (2004) Advances in functional and structural MR image analysis and implementation as FSL. Neuroimage 23 Suppl 1: S208-219.

56. Andersson JLR, Jenkinson M, Smith S (2007). Non-linear optimization. FMRIB technical report TRO7 JA1.

57. Smith SM (2002) Fast robust automated brain extraction. Hum Brain Mapp 17: 143-155.

58. Zhong Z, Deane R, Ali Z, Parisi M, Shapovalov Y, et al. (2008) ALScausing SOD1 mutants generate vascular changes prior to motor neuron degeneration. Nat Neurosci 11: 420-422.

59. Zlokovic BV (2008) The blood-brain barrier in health and chronic neurodegenerative disorders. Neuron 57: 178-201. 